\title{
VARIATION IN THE PRESENCE AND CAUSE OF DENSITY-DEPENDENT MORTALITY IN THREE SPECIES OF REEF FISHES
}

\author{
Graham E. Forrester ${ }^{1}$ and Mark A. Steele \\ Department of Organismic Biology, Ecology, and Evolution, University of California, \\ 621 Charles E. Young Drive South, Los Angeles, California 90095-1606, USA
}

\begin{abstract}
Determining the mechanisms by which natural populations are regulated is a key issue in ecology. Identifying the biological causes of density dependence has, however, proved difficult in many systems. In this study we tested whether adults of three species of reef fish (all gobies) suffered density-dependent mortality, and whether the densitydependent component of mortality was caused by predation. We used field experiments to test for density dependence in each prey species, manipulating the presence of predators and prey density in a factorial design. Prey were stocked on replicate patches of reef constructed of natural materials, with each reef receiving a different density of gobies. Predatory fishes were excluded from half of the reefs using a combination of removals and exclusion cages. Survival of the first species, Lythrypnus dalli, was high and densityindependent on reefs free of predators, but declined rapidly with increasing density on reefs to which predators had access. Density dependence in L. dalli was thus a result of mortality inflicted by predatory fishes. In the second species, Coryphopterus nicholsii, predators caused a large reduction in the survival in one experiment but had a negligible effect in a second experiment. More importantly, though, survival of $C$. nicholsii was always independent of its density, regardless of predator presence. In the final species, Coryphopterus glaucofraenum, two separate experiments showed that natural changes in adult abundance (experiment 1) and survival of stocked adults (experiment 2) were density-dependent regardless of predator presence. Both experiments thus indicated that the density-dependent component of loss in C. glaucofraenum was caused, at least in part, by an interaction other than predation. The presence, intensity, and biological cause of density-dependent survival were thus strikingly different for each of these three fishes, despite the fact that they are taxonomically closely related and ecologically similar. These findings suggest a need for further studies aimed at predicting under what circumstances different mechanisms of population regulation will operate.
\end{abstract}

Key words: coral reefs; Coryphopterus glaucofraenum; Coryphopterus nicholsii; density dependence; Gobiidae; Lythrypnus dalli; mortality; population dynamics; population regulation; predation; reef fishes; temperate reefs.

\section{INTRODUCTION}

Determining the mechanisms by which natural populations are regulated has long been a central issue in population ecology (Auerbach et al. 1995, Begon et al. 1996). Regulation occurs when there are bounds to the fluctuations in a population's abundance which protect it from extinction and result in its long-term persistence (Murdoch 1994). Except in a few special cases (Murdoch 1994), regulation results from density dependence in per capita rates of input to, or loss from, the population. It is important to determine whether there are generalities to be made about how regulation occurs in different species (Stiling 1988, Sinclair 1989). For example, is regulation commonly the result of competitive interactions, or is it more frequently a result of density-dependent mortality inflicted by predators or

Manuscript received 23 October 1998; revised and accepted 19 August 1999

${ }^{1}$ Present address: Department of Biological Sciences, Biological Sciences Center, 100 Flagg Road, University of Rhode Island, Kingston, Rhode Island 02881-0816 USA. parasites? Obtaining answers to such questions has been difficult, partly because it has been hard to construct reliable tests for density dependence in natural populations (e.g., Gaston and Lawton 1987, Turchin 1990).

The method most commonly used to identify the biological interactions that cause density-dependent mortality is life table analysis (Dempster 1983, Stiling 1988, Sinclair 1989, Auerbach et al. 1995). Life table analysis (Varley et al. 1973) is a correlative approach that is based on regressing per capita mortality against population density using a time series of data. Life table analysis has been commonly applied in studies of species with readily identifiable cohorts (Sinclair 1989), and for which causes of death can be reliably determined by observational means (Cappuccino 1992, Crawley 1992). In these cases, it has been possible to quantify different sources of mortality and identify which, if any, are density-dependent. Performing similar analyses is much more difficult for other taxa, and has rarely been attempted. 
FIG. 1. Predicted outcomes of experiments testing for predator-induced density dependence in prey survival. Interpretations of the outcome in each case are provided in the text.

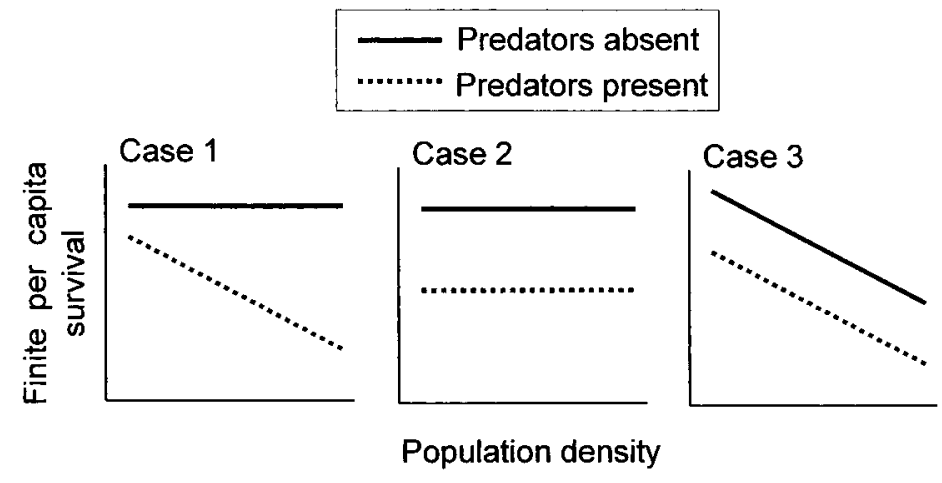

A number of shortcomings of life table analysis have been noted (e.g., Gaston and Lawton 1987), including a failure to detect density dependence when it is present (Hassell 1986, 1987, Hassell et al. 1989, Turchin 1990). As a result, several researchers have argued that experimental manipulation of population density is a more reliable method to identify density dependence (Nicholson 1957, Murdoch 1970, Sinclair 1989, Harrison and Cappuccino 1995).

Experimental tests of density-dependence are still relatively rare in many systems (Harrison and Cappuccino 1995), but have been commonly used with populations of reef fishes. Reef fishes are typical of many other benthic marine species in that the juvenile and adult stages are sedentary and occur in subdivided patches of habitat. Local benthic populations are open because they are replenished by the arrival of planktonic larvae that spend days to months in the pelagic realm and so may have originated from elsewhere. Input to the benthic population occurs when individuals take up residence in the adult habitat after the dispersive larval phase, a process referred to as settlement. Losses from benthic populations are the result of deaths of local juveniles and adults. Local benthic populations can therefore be regulated if either the rate of larval settlement or the mortality rate of benthic juveniles and adults is density dependent.

There has been considerable controversy over the strength of density dependence in reef fish populations (reviews in Sale 1991 and by Caley et al. 1996). Until recently, most experiments had failed to detect densitydependent survival in reef fishes (Doherty 1982, 1983), or found only weak negative effects (Jones 1984, 1987a, b, 1988, Forrester 1990). More recent studies have shown steeper declines in survival at high population densities (Behrents 1987, Hunt von Herbing and Hunte 1991, Tupper and Hunte 1994, Forrester 1995, Tupper and Boutilier 1995, Hixon and Carr 1997, Steele 1997, Schmitt and Holbrook 1999a, b). Our recent studies (Forrester 1995, Steele 1997) have demonstrated strong density-dependent mortality in the three fish species studied in this paper.

Although these more recent studies provide evidence that density-dependent mortality may be important in regulating populations of some reef fishes, the biological causes of this density-dependent mortality are virtually unknown (for an exception see Hixon and Carr 1997). In this study, we attempt to define the biological interaction causing density dependence in the same three species we studied previously. Specifically, we tested whether density-dependent mortality occurs among adults of our three reef fishes, and whether the density-dependent component of mortality is caused by predation. Sources of mortality are very difficult to define by observational or inferential means in reef fishes. Deaths are almost never observed directly, nor are corpses routinely available to determine causes of death. Reef fishes are also often consumed by a diverse suite of predators (Randall 1967), making it impractical to construct estimates of mortality by analyzing predator diets. We therefore took an experimental approach to test for predator-induced density dependence: we manipulated both predator presence and prey density in a crossed design.

We classified the possible outcomes of our experiment into three alternatives, assuming no positive density dependence (Fig. 1). Our hypothesis that predators alone cause density dependence would be supported if survival were high, and unrelated to density, in the absence of predation but density-dependent when prey were exposed to predators (Fig. 1, case 1). Survival that was unrelated to density regardless of exposure to predation would indicate that survival was not densitydependent under normal conditions for the test species (Fig. 1, case 2). If there was a negative relationship between density and survival in the absence of predators, then the density-dependent component of survival was, at least in part, caused by something other than predation (Fig. 1, case 3). We have drawn the relationships between survival and density as parallel in case 3; however, we include in this category cases where the slopes of the two lines are not parallel. Because we measured finite mortality over significant periods of time, whether the two lines in case 3 are expected to be parallel depends upon the order in which different mortality sources act. As a result, when the slopes of both lines are negative, as outlined in case 3 , it is difficult to isolate whether or not the predatory 
component of mortality is density dependent. For our purposes in this paper, the crucial point is that in case 3 , density-dependent mortality occurs in the absence of predators.

\section{Methods}

\section{Study system}

We studied three species of reef fishes in the family Gobiidae. Two of the species, Lythrypnus dalli (the bluebanded goby) and Coryphopterus nicholsii (the blackeye goby) occur on rocky reefs on the west coast of the United States and we studied them at Santa Catalina Island $\left(33^{\circ} 27^{\prime} \mathrm{N}, 118^{\circ} 29^{\prime} \mathrm{W}\right)$, California, USA. The third species, Coryphopterus glaucofraenum (the bridled goby), occurs on coral reefs throughout the Caribbean and warm western Atlantic, and our work on this species was done at Lee Stocking Island, Bahamas $\left(23^{\circ} 46^{\prime} \mathrm{N}, 76^{\circ} 10^{\prime} \mathrm{W}\right)$.

All three species are small, reaching maximum lengths of 50, 90, and $60 \mathrm{~mm}$ standard length (SL) for L. dalli, C. nicholsii, and C. glaucofraenum, respectively. L. dalli and C. nicholsii prefer reefs bearing little canopy forming algae, where adults may reach densities of roughly $70 / \mathrm{m}^{2}$ and $10 / \mathrm{m}^{2}$ respectively (Steele 1997; M. Steele, unpublished data). C. glaucofraenum is found in areas of sand, interspersed with reef and rubble. Adults occur at densities up to 10 individuals/ $\mathrm{m}^{2}$ at sites near Lee Stocking Island, but may reach 15 individuals $/ \mathrm{m}^{2}$ at sites in the Caribbean (Forrester 1995; G. Forrester, unpublished data). Juveniles and adults of all three species maintain home ranges no greater than a few square meters, within which they feed on invertebrates: $L$. dalli eats primarily zooplankton, $C$. nicholsii eats both zooplankton and benthic invertebrates, and C. glaucofraenum primarily eats benthic invertebrates. Another shared behavior is the use of crevices in the reef both as refuges from predators, and as nest sites within which males guard nests of demersal eggs. After hatching, larval $L$. dalli and $C$. nicholsii are planktonic for 2-3 mo before settling to adult habitat (M. Steele, unpublished data) and C. glaucofraenum spends about one month in the plankton (Sponaugle and Cowen 1994). Settlement of the two species of Coryphopterus occurs year-round at our sites, with the majority occurring during summer (M. Steele and G. Forrester, unpublished data). L. dalli settles from June to January, with a peak in August to September (Behrents 1983; M. Steele, unpublished data). At settlement, L. dalli is $9-11 \mathrm{~mm} \mathrm{SL}$ (Behrents 1987), C. nicholsii is $15-25 \mathrm{~mm}$ SL (M. Steele, unpublished data), and C. glaucofraenum is $6.5-8 \mathrm{~mm}$ SL (G. Forrester and M. Steele, unpublished data). $L$. dalli and $C$. glaucofraenum mature at relatively small sizes (about 20 and $25 \mathrm{~mm} \mathrm{SL}$, respectively) (St. Mary 1993; K. S. Cole, personal communication) and have short life spans (1-2 yr.) (Behrents 1983; G. Forrester and M. Steele, unpublished data). The larger C. ni- cholsii does not mature until reaching at least $45 \mathrm{~mm}$ SL and may live up to 5 years (Wiley 1973).

At Santa Catalina Island, the main predator of $L$. dalli and C. nicholsii is the kelp bass (Paralabrax clathratus family Serranidae) which comprises about $90 \%$ of all piscivorous fishes at that site (M. Steele, unpublished data). In the sandy habitats where we conducted our experiments, the barred sand bass (Paralabrax nebulifer) may also prey upon the gobies. In the course of a day, these two predators move from tens to hundreds of meters and so might visit several of the small reefs that we used in this study. At Lee Stocking Island, the suite of potential predators of $C$. glaucofraenum is much more diverse, and it is difficult to confirm which of them actually consume this goby. We assumed that most of the predators of C. glaucofraenum are larger piscivorous fishes (Randall 1967). On the isolated reefs we used in this study, these piscivorous fishes can be divided into two types: predators that remain resident on one patch reef, and mobile predators that routinely travel between reefs and make only short visits to any one. Resident predators include Nassau groupers (Epinephelus striatus), graysbys (E. cruentatus), coneys ( $E$. fulvus), squirrelfish (Holocentrus ascensionis and $H$. rufus), and moray eels (Gymothorax moringa). The most common transient predators are jacks (Caranx ruber and $\mathrm{C}$. bartholomaei) and lane snappers ( $\mathrm{Lu}$ tjanus synagris), plus rarer lizardfish (Synodus spp.).

\section{General approach}

The basic approach we used to test whether predators influenced the relationship between the density of adult gobies and their survival was the same for each of our study species, though the details differed in each case (Table 1). For each species, we used isolated patch reefs constructed of natural materials as replicate units of habitat for the gobies. To isolate the effects of predators, we excluded them from half of the reefs using both removals and exclusion cages. Within each predator treatment, we established a continuous range of adult goby densities by stocking a different number of adult gobies on each reef. In each case, the densities ranged from very low up to approximately the maximum we have observed for each species.

\section{Experiment on Lythrypnus dalli}

The experiment on $L$. dalli at Santa Catalina was done in August-September 1996 using square reefs (1 $\times 1 \mathrm{~m}$ ) constructed of natural rock rubble. Reef materials were transported from nearby areas and placed on a plastic mesh base to prevent them from sinking into the underlying sand. The number and size distribution of rocks used was the same for all reefs to standardize the habitat available to the gobies. A total of 16 reefs were built in a $2 \times 8$ grid in a sandy bay, at depths from 9 to $13 \mathrm{~m}$. Each reef was isolated by at least $10 \mathrm{~m}$ from its nearest neighbor and at least $20 \mathrm{~m}$ from the nearest natural reef. $L$. dalli has rarely been 
TABLE 1. Summary of the experiments testing for predator-induced density-dependent mortality in three goby prey species.

\begin{tabular}{|c|c|c|c|c|c|c|c|}
\hline Prey species & $\begin{array}{c}\text { Experi- } \\
\text { ment }\end{array}$ & $\begin{array}{c}\text { Date } \\
\text { conducted }\end{array}$ & $\begin{array}{l}\text { Predator } \\
\text { treatments } \\
\text { (categorical } \\
\text { factor) }\end{array}$ & $\begin{array}{c}\text { Goby density } \\
\text { treatments } \\
\text { (covariate) }\end{array}$ & $\begin{array}{c}\text { Response } \\
\text { variable }(\%)\end{array}$ & $\begin{array}{l}\text { Gobies } \\
\text { tagged? }\end{array}$ & $\begin{array}{l}\text { Dura- } \\
\text { tion of } \\
\text { experi- } \\
\text { ment (d) }\end{array}$ \\
\hline L. dalli & 1 & 1996 & $\begin{array}{l}\text { present } \\
\text { absent } \dagger\end{array}$ & 8 levels & survival & yes & 21 \\
\hline \multirow[t]{3}{*}{ C. nicholsii } & 1 & summer 1996 & $\begin{array}{l}\text { present } \\
\text { absent } \dagger\end{array}$ & 8 levels & survival & yes & 30 \\
\hline & 2 & fall 1996 & $\begin{array}{l}\text { present } \\
\text { absent } \dagger\end{array}$ & 8 levels & survival & yes & 59 \\
\hline & 3 & winter 1996 & present & 16 levels & survival & yes & 140 \\
\hline \multirow[t]{2}{*}{ C. glaucofraemum } & 1 & 1995 & $\begin{array}{l}\text { present } \\
\text { absent } \ddagger \\
\text { cage control§ }\end{array}$ & not manipulated & $\begin{array}{l}\text { change in } \\
\text { abundance }\end{array}$ & no & 55 \\
\hline & 2 & 1996 & $\begin{array}{l}\text { present } \\
\text { absent } \ddagger\end{array}$ & 8 levels & remaining & no & 30 \\
\hline
\end{tabular}

$\dagger$ Predators were excluded by enclosing reefs in cages.

\$ Site-attached predators were removed from reefs, and mobile predators were excluded by enclosing reefs in cages.

$\S$ Site-attached predators were present on reefs with control cages, and mobile predators were allowed access to reefs.

observed to traverse expanses of open sand this wide in previous studies (Steele 1997, 1998). In order to exclude kelp bass and other predators we surrounded half of the reefs with cages, which were assigned systematically, so that caged reefs alternated with uncaged reefs along the two rows of 8 eight reefs. Cages were $1.5 \times 1.5 \times 0.5 \mathrm{~m}$ high and constructed of clear nylon monofilament netting (mesh size $=9.5 \mathrm{~mm}$ ) on PVC pipe ( $25 \mathrm{~mm}$ outer diameter) frames.

The experimental reefs were initially unoccupied, and $L$. dalli stocked on the reefs were collected from a natural reef roughly $1 \mathrm{~km}$ from the experimental site. All fish used in the experiment ranged in length from 20 to $44 \mathrm{~mm}$ SL, and so should all have been sexually mature (St Mary 1993). Reefs were stocked with groups of fish that were similar in both their mean size and their range of sizes. All gobies were tagged prior to stocking, so that we could track their fate as closely as possible. We tagged the gobies subcutaneously in the nape of the neck with a single mark of colored elastomer (Northwest Marine Technology Inc., Shaw Island, Washington, USA; see Frederick 1997 for details), which allowed us to separate them from other fish, but did not allow us to recognize them as individuals. After tagging, the gobies were transplanted to the experimental reefs at densities ranging from 4 individuals $/ \mathrm{m}^{2}$ to 65 individuals $/ \mathrm{m}^{2}$. We assigned density treatments at random within the two predator treatments.

For the first 24 hours after they were transplanted onto the reefs, the gobies on all 16 reefs were protected with cages to allow the fish to establish themselves in their new environment in safety. The experiment began when cages on the "predators present" reefs were removed, and ran for 21 days. We censused the gobies on 15 of those days in order to keep track of their movements. Visual counts of $L$. dalli are usually underestimates though, because they spend some of their time hidden in crevices. We therefore dismantled the reefs and captured all of the gobies on the last day of the experiment to measure the final number of survivors. The presence of elastomer tags was used to distinguish stocked adults from recruits that settled from the plankton and immigrants from nearby natural reefs. Movements of tagged gobies from one experimental reef to another could, however, not be assessed because all stocked gobies received the same mark.

\section{Experiments on Coryphopterus nicholsii}

We conducted two experiments on $C$. nicholsii; the first in July-August 1996 and the second from in October-December 1996. In both cases, we used the same $1 \times 1 \mathrm{~m}$ rock rubble reefs that were used for the experiment on $L$. dalli. The cages we used to exclude predators were constructed of rigid plastic mesh (mesh size $=19 \mathrm{~mm}$ ) and were $1 \times 1 \times 0.67 \mathrm{~m}$ high. This cage design has been shown to be free of artifacts for C. nicholsii and permits reliable assessment of predator effects (Steele 1996).

C. nicholsii used in both experiments were collected from natural reefs within $2 \mathrm{~km}$ of the experimental site. In the first experiment, we stocked the experimental reefs with subadult gobies that ranged from 35 to 45 $\mathrm{mm} \mathrm{SL}($ mean $=38.5 \mathrm{~mm})$. By the end of the experiment a month later, most or all of the surviving residents had grown to a size at which they should have been mature. In the second experiment, we used larger subadults and adults ranging from 40 to $50 \mathrm{~mm} \mathrm{SL}$ $($ mean $=44.2 \mathrm{~mm})$, all of which should have been sexually mature by the end of the first month of the experiment. In both experiments, the stocking densities ranged from 2 to 15 gobies $/ \mathrm{m}^{2}$ and we strove to stock groups of fish with similar mean sizes on each reef (range of means: $36.0-39.3$ and $42.5-46.5 \mathrm{~mm}$ in experiments 1 and 2, respectively).

The first experiment on $C$. nicholsii began as soon 
as the gobies were stocked on the reefs. They therefore had no time to acclimate to the reefs and the fish on the uncaged reefs were exposed to predators immediately after being transplanted. This may have increased the rate of early loss to predators (see Results: Coryphopterus nicholsii), so for the second experiment we placed cages around all reefs for the first 24 hours after stocking. Before the second experiment, we also added more rocks to each of the reefs to provide more crevices for the gobies to shelter in. The second experiment thus began when the temporary cages were removed from the reefs designated as open to predation.

We tagged all $C$. nicholsii before transplanting them to the reefs using visual implant tags (Northwest Marine Technology Inc.). These tags are pieces of plastic film $(1 \times 2.5 \mathrm{~mm})$ that are injected under the skin. Each tag bears a unique 3 digit alphanumeric code that can be read by divers. The first experiment ran for 31 days and we surveyed the reefs on days 1-5, 14, 24, 30 , and 31 to locate the tagged fish and any immigrants (identified by the lack of a tag). We also searched nearby natural reefs for any tagged fish that emigrated from the experimental reefs. To construct final density estimates and confirm our reading of the visual implant tags, we also made a thorough search of the reefs on day 31 , during which we caught and removed all gobies encountered. A follow-up search on day 32 confirmed that we had accounted for all adult gobies on the reefs. We ran the second experiment for longer than the first (59 days instead of 31), and visual surveys of the experimental reefs were made on days $1,10,24,31,45$, and 57. On day 59 we searched surrounding habitats within $30 \mathrm{~m}$ of the experimental reefs for any tagged fish that had emigrated. Once during the experiment (day 32), and again at its end (day 59), we collected all adult gobies on the reefs to assess their density. Captured gobies were measured and inspected for tags in situ, and then immediately returned to their point of capture.

For logistic reasons, we were unable to maintain the predator exclusion beyond 59 days. We decided, however, to leave the remaining gobies on the reefs after the cages were removed, and measured their survival over an additional 140 days (from December to May). The starting densities for this final period were, of course, slightly lower than those at the start of experiments 1 and 2 (range $=1-12$ per $\mathrm{m}^{2}$ ), fish were larger (all were adults, ranging in size from $50 \mathrm{~mm}$ to $65 \mathrm{~mm}$ $\mathrm{SL}$ ), and all reefs were exposed to predators. We checked the experimental and surrounding reefs for migrants on days 77 and 140, and all tagged gobies on the study reefs were collected on day 140 .

\section{Experiments on Coryphopterus glaucofraenum}

The experiments on C. glaucofraenum in the Bahamas were done using a set of 32 patch reefs constructed west of Norman's Pond Cay in a shallow (2$4 \mathrm{~m}$ deep) sandy area (Carr and Hixon 1995). All of the reefs are isolated by at least $200 \mathrm{~m}$ from any other. Each reef consisted of several live coral heads (Porites and Agaricia) that were translocated from nearby areas and arranged on the sand to create a reef roughly 2.5 $\mathrm{m}$ in diameter $\left(\right.$ area $\left.=4.9 \mathrm{~m}^{2}\right)$. The reefs were constructed from 1991 to 1994, and have since been colonized naturally by fish assemblages representative of natural patch reefs in the area (M. Carr and M. Hixon, unpublished data).

In June-September 1995, we conducted an experiment to test for effects of predators on changes in the abundance of unmanipulated goby populations. Resident predators were manipulated by removing them from six reefs using anaesthetic and nets, and transplanting them to natural reefs several kilometers from the experimental site. Transient predators were excluded from these reefs by constructing large $(6.5 \mathrm{~m}$ diameter) cylindrical cages around reefs that extended from the sea floor to the surface of the water. The cages were constructed of knotless nylon netting, of a mesh size $(9.5 \mathrm{~mm})$ that was large enough to allow free passage of gobies. Cages were weighted with chain at the bottom to seal them to the sediment, and the walls were supported by floats. Six control reefs were unmanipulated and six other reefs were surrounded with "control" cages, which consisted of panels of netting that extended from the sand to the surface and were spaced around the reef in a circle (diameter $=6.5 \mathrm{~m}$ ), but only partially enclosed the reef. These cage control reefs were occupied by resident predators, which we did not remove.

In this experiment, we did not manipulate the density of gobies. Instead we simply censused the adult gobies ( $>25 \mathrm{~mm} \mathrm{SL}$ ) that were naturally present on the reefs just before the manipulations, and then again 55-64 days later. Tests where visual counts were followed up with thorough collections indicate that adult C. glaucofraenum on small patch reefs can be censused reasonably accurately on scuba (G. Forrester, unpublished data).

In 1996 we conducted a second experiment designed to test effects of predator presence and adult goby density on the survival of adult gobies. We manipulated the presence of resident and transient predators in the same way as in 1995, except that we added two more reefs per treatment, which yielded eight predator exclusion reefs and eight reefs to which predators had access. To vary the density of adult $C$. glaucofraenum we stocked a different number of adults $(25-55 \mathrm{~mm}$ SL) on each reef. Prior to adding the experimental fish, we removed all juveniles (12-25 mm SL) and adults that were already occupying the reefs. We also removed all large (25-60 mm SL) individuals of an ecologically similar goby (Gnatholepus thompsoni), because they might have influenced the outcome of the experiment. After all resident gobies were removed we transplanted gobies from other sites to the experimental reefs at densities ranging from $0.8-13.6$ individuals $/ \mathrm{m}^{2}$. A 


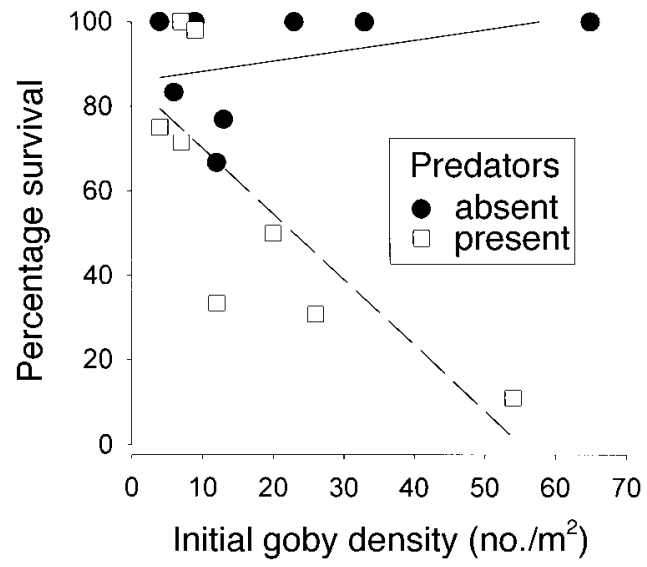

FIG. 2. The relationship between the initial density of stocked adult $L$. dalli and their subsequent survival on reefs from which predators were excluded $(n=8)$ or were allowed free access $(n=8)$.

roughly similar mean and range of sizes of C. glaucofraenum was stocked on each reef. The experiment ran for 30 days. We did not tag the transplanted gobies, which means that we cannot distinguish among mortality, emigration, and immigration. However, in previous studies where this species was stocked on habitat patches that were isolated by only $10 \mathrm{~m}$ of sand, rates of successful immigration were $<4 \%$ (Forrester 1995; G. Forrester, unpublished data). The reefs in this study were isolated by $200 \mathrm{~m}$, so it seems very unlikely that much successful migration occurred.

\section{Statistical analyses}

We tested our hypothesis that predators induced density dependence with analyses of covariance (ANCOVA). In these analyses, there were two factors: predator presence (a categorical variable), and goby density (a continuous variable, i.e., a covariate). The interaction term was used to test whether the slope of the relationship between density and survival differed between predator treatments. If the interaction term was not significant, we dropped it from the model and then tested for an effect of predators on survival and for an effect of conspecific adults on survival (assuming a linear relationship).

\section{RESULTS \\ Lythrypnus dalli}

Only a single $L$. dalli immigrated from a nearby natural reef onto the experimental reefs, and none of the tagged experimental fish were found to have emigrated to natural reefs. This, coupled with the negligible rates of migration $(\approx 1 \%)$ among similar reefs seen in previous studies (Steele 1998), suggests that virtually all losses from the reefs were due to mortality. A significant interaction term in the ANCOVA indicated that the relationship between goby survival and density differed depending on the presence of predators $\left(F_{1,12}=\right.$
11.3, $P=0.006)$. This was because survival in the absence of predators was uniformly high at all densities (regression; $r^{2}=0.14, P=0.36$ ) (Fig. 2). In contrast, the density of gobies on reefs exposed to predators declined steadily throughout the experiment, and survival over the entire 21 days of the experiment decreased as the density of gobies increased (regression, $r^{2}=0.62, P=0.02$ ). This pattern of results indicates clearly that predators induced density-dependent survival in L. dalli (Case 1 in Fig. 1).

\section{Coryphopterus nicholsii}

In the first experiment on $C$. nicholsii, we detected no migration of the tagged transplanted gobies, so we assumed that all losses occurred via death on site. A non significant interaction term in the ANCOVA indicated that the relationship between density and survival did not differ in slope between the two predator treatments (ANCOVA, $F_{1,12}=0.91, P=0.35$ ) (Fig. $3 a)$. The survival of gobies was uninfluenced by density (ANCOVA, $F_{1,13}=0.32, P=0.58$ ) and was density independent both in the absence of predation (regression, $\left.r^{2}=0.02, P=0.77\right)$ and when predators were present (regression, $r^{2}=0.14, P=0.37$ ) (Fig. 3a). Although the survival of gobies was uninfluenced by density, it was reduced quite dramatically by predation (ANCOVA, $F_{1,13}=51.7, P<0.0004$ ). Few gobies survived on reefs exposed to predators (mean survival $\pm 1 \mathrm{SE}=12 \% \pm 8 \%$ ), but almost all of the gobies protected from predation survived the experiment (mean $\pm 1 \mathrm{SE}=88 \% \pm 7 \%$ ).

Our visual censuses indicated that much of the losses on the uncaged reefs occurred within a few days of the start of the experiment. We attribute much of this loss to predatory kelp bass, which were observed foraging on these reefs in higher numbers than usual during this period. The gobies may have been particularly vulnerable early on because they were not given any time to establish themselves on the reefs before the experiment began. In our second experiment we took steps to make the gobies less vulnerable, by providing more refuge and allowing them more time to establish themselves in safety. During the second experiment we detected some movement of tagged gobies, but confirmed migrations accounted for a low percentage of the overall loss from the reefs (13\% of losses). As in the first experiment, the relationship between the survival of $C$. nicholsii and their density was not affected by predator presence (ANCOVA interaction, $F_{1,12}=0.001, P=$ 0.99). C. nicholsii exhibited density-independent survival (ANCOVA, $F_{1,12}=0.002, P=0.97$ ), illustrated by the lack of a relationship between survival and density in either of the treatments (regression with predators, $r^{2}<0.001, P=0.97$; regression without predators, $r^{2}<0.001, P=0.98$ ) (Fig. 3b). Unlike the first experiment, predation had a negligible influence on goby survival in the autumn (ANCOVA, $F_{1,13}=0.20$, $P=0.67)$. The second experiment thus differed from 


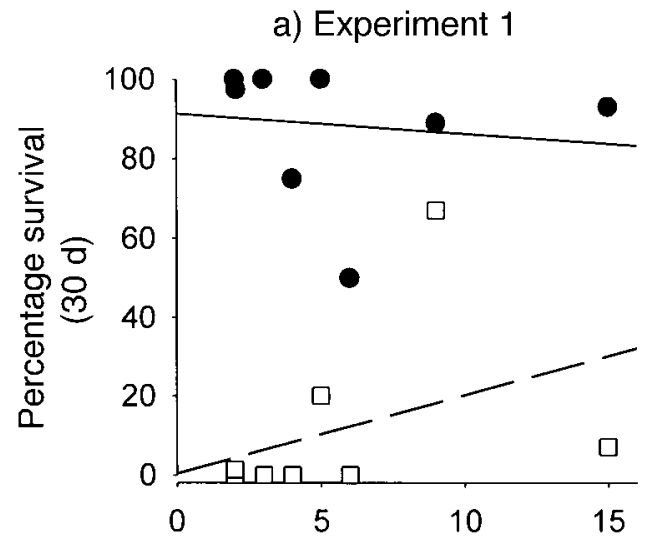

b) Experiment 2, days 1-59

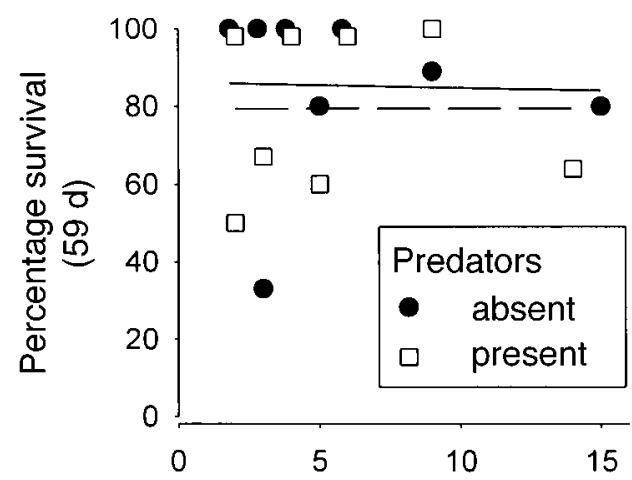

c) Experiment 2, days $60-199$

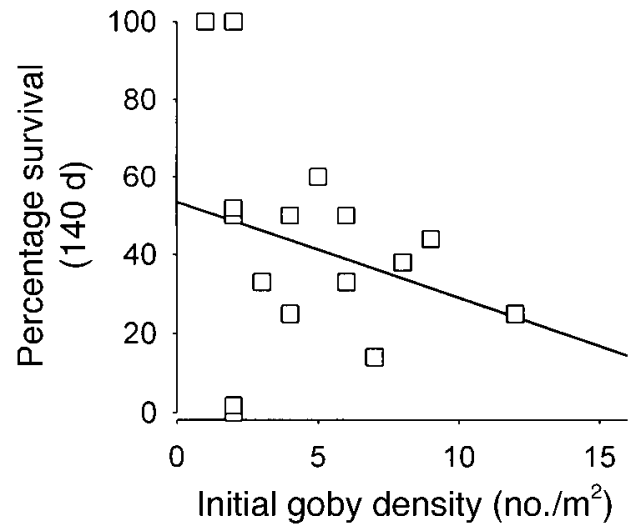

FIG. 3. The relationship between the initial density of stocked adult $C$. nicholsii and their subsequent survival on reefs from which predators were excluded or were allowed free access. (a) Experiment 1 was performed during the summer of 1996 and (b) experiment 2 was done from the autumn of the same year until spring 1997. Predation treatments were maintained for only the first 59 days of experiment 2 . For the following 140 days (c) predators had access to all reefs. Initial density refers to density on (a and b) day 0 or (c) day 60 . For each of the two predation treatments, $n=8$ in panels (a) and (b), and in panel (c), $n=16$. the first in the intensity of predation on the gobies, but was similar in that survival was always density independent.

Although we were unable to maintain the predator exclusion beyond 59 d, we continued to measure the survival of the remaining gobies on all 16 reefs over another 140 d (from December to May). Gobies continued to disappear steadily from the reefs, and the pattern of loss from reefs was very similar to that in the previous experiments: migration over the winter accounted for $16 \%$ of losses from the experimental reefs and the gobies' survival remained unrelated to their density (regression, $r^{2}=0.003, P=0.84$ ) (Fig. $3 \mathrm{c}$ ). Adult $C$. nicholsii thus never displayed densitydependent survival, either predator-induced or otherwise (Fig. 1, case 2).

\section{Coryphopterus glaucofraenum}

The first experiment in 1995 revealed no detectable difference among predation or cage-control treatments in the slope of the relationship between the initial density of adult bridled gobies and their change in abundance over the duration of the experiment (ANCOVA, $\left.F_{2,12}=1.58, P=0.86\right)$. With the interaction term removed from the ANCOVA model, we detected a significant overall negative relationship between the initial density of adult bridled gobies and their change in abundance over the duration of the experiment (ANCOVA, $F_{1,14}=12.4, P=0.003$ ). Reefs initially occupied by more gobies were likely to decline in abundance, whereas those reefs initially occupied by few gobies tended to accumulate more adults, probably by the growth of juveniles into adult size during the experiment (Fig. 4). This density-dependent relationship occurred regardless of whether predators were present or absent, and on cage-control reefs (Fig. 4). In addition, the change in abundance of the gobies was affected significantly by the predator manipulation (ANCOVA, $F_{2,14}=4.3, P=0.035$ ). Gobies exposed to predators showed more negative changes in abundance than those protected from predation, indicated by a significant difference in the elevation of the two regression lines (Tukey's test, $P=0.037$; Fig. 4).

A second goal of the 1995 experiment was to test for artifacts of caging on C. glaucofraenum. The reefs with control cages had resident predators present, and should have allowed free access to transient predators. If there were no effects of caging, then gobies on these reefs should show changes in abundance that were not different from those on reefs to which predators had unrestricted access, and this was indeed the case (Tukey's test, $P=1.0$ ). Since predators reduced the abundance of gobies, we would also expect gobies on cagecontrol reefs (with predators) to be reduced in abundance compared to those on predator-free reefs. The average change in abundance did not, however, differ significantly between these two treatments (Tukey's test, $P=0.23$ ), making this part of the test for caging 


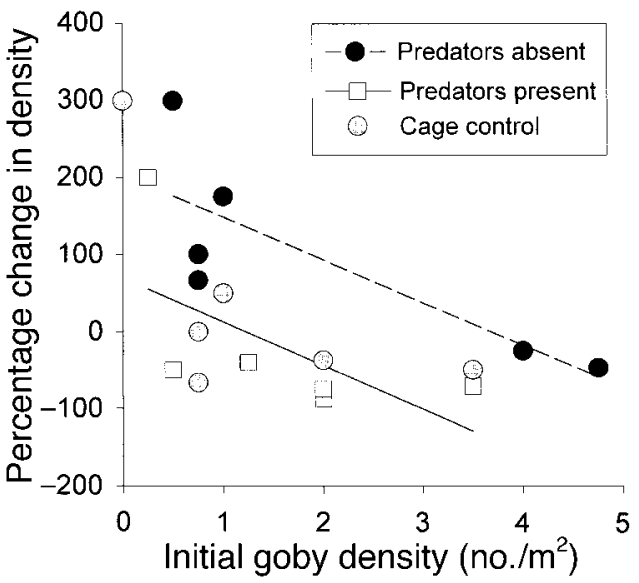

FIG. 4. Effects of predatory fishes and predator-exclusion cages on changes in the abundance of adult $C$. glaucofraenum in 1995. Goby densities were not manipulated. The change in density of adult gobies on a reef is plotted as a function of their initial density for each treatment. Regression lines are displayed for the predators-present $(n=6)$ and predatorsabsent $(n=6)$ treatments only. The predators-absent treatment was established by removing sedentary predators from reefs and enclosing the reefs with exclusion cages. Cage control reefs $(n=6)$ were occupied by sedentary predators and were surrounded with partial cages that allowed free access to mobile predators.

artifacts equivocal. Nonetheless, the results do suggest that there were no major artifacts of caging (Fig. 4).

In the 1996 experiment on C. glaucofraenum, when we manipulated the density of adult gobies, there was no significant interaction between the effects of predators and density on survival (ANCOVA, $F_{1,12}=1.9$, $P=0.19$ ), suggesting that the relationships between density and survival had similar slopes on reefs with and without predators. The mean survival of C. glaucofraenum was significantly lower on reefs open to predators than on predator-free reefs (ANCOVA, $F_{1,13}$ $=19.5, P=0.001)$. The percentage of stocked gobies remaining on reefs was also affected by their density (ANCOVA, $F_{1,13}=12.13, P=0.004$ ). Far fewer gobies survived on reefs with high initial densities, than on reefs initially stocked with few gobies (Fig. 5). It is clear though, that much, if not all, of the density dependence in the survival of $C$. glaucofranum is not due to predation by the piscivores we excluded. Overall then, the results of both the 1995 and 1996 experiments on C. glaucofraenum suggest that density-dependence occurs on reefs both with and without predatory fishes (Fig. 1, case 3).

\section{Discussion}

\section{Possible experimental artifacts}

The main goal of this study was to determine whether mortality was density-dependent, and whether predators were the cause of density-dependence. Any experimental artifacts that might themselves cause density-dependence, or obscure any density-dependence in predation, would compromise this goal. One potential source of artifactual results was the use of cages to manipulate exposure to predators (Virnstein 1978, Peterson 1979, Dayton and Oliver 1980, Underwood and Denley 1984). Previous research on C. nicholsii (Steele 1996) and the 1995 experiment on C. glaucofraenum indicated no obvious caging artifacts for these species. Lythrypnus dalli, however, showed an artifactual response to cages in previous experiments. Gobies immigrated preferentially to reefs enclosed with small, black-meshed cages that obviously reduced light levels (Steele 1996). We tried to avoid this problem in the current study by using larger cages built of very fine, clear, netting, which neither provided obvious vertical structure nor noticeably reduced light levels. In addition, since we observed virtually no movement among reefs it seems unlikely that a cage-induced bias in migration could have affected our results.

\section{Differences among the three gobies in the strength and cause of density dependence}

The major finding of our study was that the three species we studied displayed striking differences in the intensity and causes of density-dependent survival. The fact that almost all mortality of $L$. dalli in our experiment was due to predation makes the results for this species easy to interpret: adult $L$. dalli show strong, spatially density-dependent mortality that is caused by predators. This conclusion is corroborated by the results of previous experiments on $L$. dalli. Survival of this goby was density-independent following a manipulation of their abundance on reefs free of predators (Steele 1998), but strongly density-dependent in a similar experiment performed later on reefs exposed to predators (Steele 1997). We are also confident that mortality rates were close to natural in the experiment on

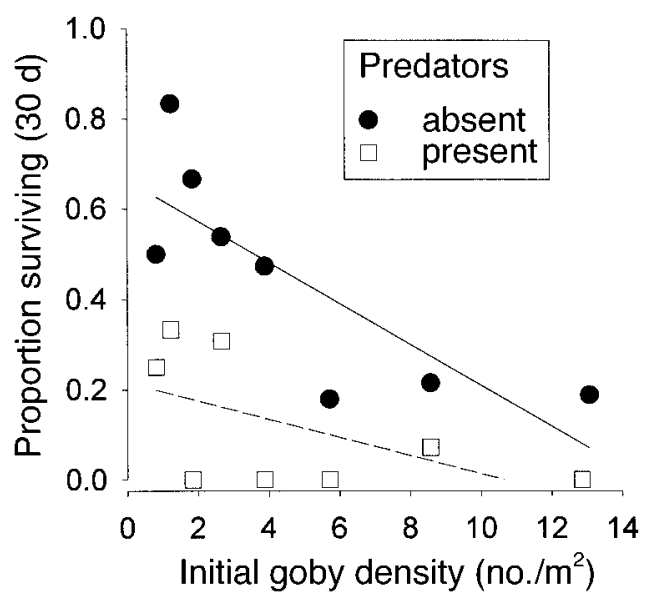

FIG. 5. The relationship between the initial density of stocked adult C. glaucofraenum and their subsequent survival on reefs in 1996. The survival of gobies was measured on reefs from which predators were excluded $(n=8)$ or were allowed free access $(n=8)$. 
L. dalli since survival was essentially identical (and near $100 \%$ ) at low densities on reefs both with and without predators. Moreover, the severe mortality of $L$. dalli in the highest density populations exposed to predators is consistent with our observations of similar cobble habitats in nature. Very high densities of $L$. dalli persist for long periods in nature only in habitats providing far more shelter than the ones we used (M. Steele, personal observation).

How do predators cause density dependence in $L$. dalli? It is unlikely, because of the short duration of the experiment and the open population structure of the dominant predator (kelp bass), that density dependence was due to a numerical or developmental responses of predators. Kelp bass may, though, show a type III functional response (Holling 1959) or an aggregative response (Hassell and May 1974) to goby density. If somatic growth is density-dependent and smaller gobies are either more vulnerable to predators than larger gobies, or attract predators more strongly, then overall mortality due to predation will be density-dependent. We view this possibility as unlikely for $L$. dalli because, even though its growth is density-dependent (Steele 1998), its risk of predation is not influenced by size over the range of sizes used in the present study (Steele 1996).

The impact of predation on $C$. nicholsii, the second species we studied, differed greatly among the two experiments. We suspect that the rapid, and high, mortality of transplanted gobies in the first experiment was an artifact of transplantation. These gobies are strongly site-attached and familiarity with their home range may be important to successful predator avoidance. By not giving the $C$. nicholsii time to acclimate their new reefs in the first experiment we may have caused mortality to be unnaturally elevated. This probable bias in the absolute mortality rate seems unlikely to have influenced our main, and consistent, finding about C. nicholsii: that adult mortality was always density independent.

Although we detected no density dependence in this study, survival of $C$. nicholsii declined strongly at high densities in a previous experiment (Steele 1997; M. Steele, unpublished data). Both studies used generally similar approaches, but subtle differences in their design and methods might explain the different outcomes. One difference was that smaller fish were used in the prior study $(18-30 \mathrm{~mm})$ than in the present study $(>$ $35 \mathrm{~mm}$ ). Density-dependent mortality might, thus, occur only in smaller size -classes of $C$. nicholsii. Another possible reason for the different outcomes was a change in the availability of refuge space for the gobies. For the second experiment in this study we used larger reefs than in the prior study (Steele 1997), which provided an increased number of the crevices used as shelter (Steele 1999). The results are, thus, also consistent with the hypothesis that density-dependent mortality occurs only when there is a shortage of refuges. Further re- search will, therefore, be needed to explain why mortality of $C$. nicholsii was only intermittently related to population density, and which agent of mortality is responsible for density dependence when it occurs.

The fact that mortality of C. glaucofraenum, our third study species, was density-dependent in populations exposed to predators is consistent with the results of two previous experiments on this species (Forrester 1995; G. Forrester, unpublished data). Our main aim was to determine whether large piscivores were the cause of this density dependence in mortality. The key result of the 1996 experiment was, therefore, that mortality in adult $C$. glaucofraenum was also density dependent in the absence of piscine predators. The results of the 1995 experiment corroborate this conclusion, because changes in adult abundance on predator-free reefs were also density dependent. These density-dependent changes in abundance may have been caused by faster growth of juveniles into adult size classes on low density reefs, rather than by reduced adult mortality. The qualitative similarity in the results of both experiments is, however, compelling. The density-dependent component of mortality that occurred in our predator-free treatments has several possible causes. Density-dependent loss might be due to competition for limited space or food, parasitism, or disease, or may have been inflicted by small predatory fishes or invertebrates that we were not able to include in our predator manipulation. At present, we cannot distinguish between these possibilities.

\section{General patterns in the timing of density dependence}

We detected density-dependent mortality in the adult stage for two of our three study species. It is difficult, though, to assess the prevalence of density-dependent mortality during the adult phase in reef fishes because most previous studies have tested for density-dependent mortality only in juveniles and have ignored adults (e.g., Doherty 1982, 1983, Jones 1984, 1987a, b, 1988, Behrents 1987, Forrester 1990, Hunte von Herbing and Hunte 1991, Tupper and Hunte 1994, Tupper and Boutilier 1995, Schmitt and Holbrook 1996, 1999a, $b$, Hixon and Carr 1997).

In a review of many animal groups, Sinclair (1989) found that density-dependent mortality occurred more frequently late in the life cycle of taxa with low reproductive rates, such as mammals and birds. In species with higher reproductive rates, such as insects and fish, density dependence was more common early in life. Large commercially exploited fishes conform to this pattern because density-dependent mortality has frequently been detected during the larval and juvenile phase, but virtually no cases of density-dependent survival in adults have been found (reviews by Bailey 1994, Bailey and Houde 1989, Myers and Cadigan 1993, Cushing 1995, Myers 1997). Of course, heavily exploited marine populations may not provide strong tests for density-dependent survival in the adult phase 
under natural conditions because of the heavy fishing mortality they experience (Rijnsdorp 1994). Our limited inspection of the literature on freshwater fishes and unexploited marine species also supports the view that density-dependent mortality occurs most often early in the life cycle, so this may be a generality that will hold true for many types of fishes (e.g., Weatherley 1972, Gulland 1977, Elliott 1994, Tonn et al. 1994, Sano 1997, Elliott and Hurley 1998). The possibility that reef fishes may prove an exception to this pattern is thus a topic worthy of further study.

\section{General patterns in the causes of density dependence}

Although some general trends in the timing of density dependence have been identified, few comparable generalities have emerged about the causes of density dependence. In a broad-based review, Sinclair (1989) concluded that their was insufficient evidence to assess the prevalence of different causes of density dependence. He noted that predation had not been adequately studied as a possible cause in any animal group, and that parasitism and disease had been almost completely overlooked. Reviewers of work on insects, a group for which these underrepresented factors have received the most attention, also concluded that there were no obvious generalities to be drawn from the available data (Dempster 1983, Stiling 1988, Cappuccino 1991, Auerbach et al. 1995). Only one review has noted a clear pattern in the relative frequency of different causes of density dependent mortality (Harrison and Cappuccino 1995). This review differed from the aforementioned reviews in being based on experimental tests for density dependence, rather than mostly on census or life-table studies. Density dependence was detected far more frequently in the experimental studies compiled by Harrison and Cappuccino (1995), and "bottom-up" interactions involving prey or host resources were the most common cause of density dependence.

Wider use of the experimental approach we took might help us to better identify patterns in the causes of density dependence for two reasons. Firstly, more experimental studies should resolve the apparent difference between the findings of past reviews focusing on descriptive and manipulative tests (Stiling 1988, Sinclair 1989, Harrison and Cappuccino 1995). Secondly, most previous studies on the causes of density dependence, both experimental and descriptive, have used species for which causes of death could be determined by observational means and so have been applied to a quite restricted set of taxa (Cappuccino 1992, Crawley 1992). Our work, and that of others (e.g., Hixon and Carr 1997), shows that experiments isolating specific mortality sources can feasibly be combined with manipulations of population density. In addition to predation, other factors such as food and shelter resources, can also be manipulated in combination with population density to isolate their effects (e.g., Forrester 1990). This experimental approach can thus be used to identify the causes of den- sity dependence in a much broader array of species than have been tested to date.

We chose our three study species because, in addition to being closely related taxonomically, they also share some key features of their ecology. They are, for example, all benthic site-attached fishes that use crevices as refuges. We predicted that they might, therefore, show similar interactions with predators that would lead to density-dependent survival. The fact that they differed in this respect highlights the need for further comparative work on a broader array of species. Even species occupying the same general habitat may show striking differences in the causes of density dependence. Working at the same reefs where we studied C. glaucofraenum, Hixon and Carr (1997) showed that the densitydependent juvenile mortality in Chromis cyanea, a small damselfish, was due entirely to piscivorous fishes. These predators also inflicted significant mortality on C. glaucofraenum, but were, at most, only partially responsible for density dependence in goby survival.

\section{Implications for population dynamics}

For two of our study species we have demonstrated spatial density dependence in mortality (sensu StewartOaten and Murdoch 1990). The question now is whether spatial density dependence will translate to temporal density dependence (sensu Stewart-Oaten and Murdoch 1990). In other words, when a collection of habitat patches is considered as a whole, will that larger population be regulated through time because increases in population density are followed by increases in mortality? Studies of insect populations indicate that density-dependent interactions may be explicit to certain spatial scales, and not observable at smaller or larger scales (Heads and Lawton 1983, Freeman and Smith 1990, Rothman and Darling 1990, Freeman and Smith 1990, Hopper et al. 1991, Stiling et al. 1991, Ray and Hastings 1996). Analyses suggest that these interactions causing within-generation spatial density dependence may be hard to detect from long-term studies that average across patches, but may nevertheless have a stabilizing effect on abundance (Hassell 1987, Alvarez-Buylla 1994, Ray and Hastings 1996) and strongly influence population dynamics (Possingham et al. 1994). The point we wish to emphasize in closing is that focusing on causes of density dependence will be valuable in future studies because many of the biological interactions causing density dependence will be scale and context dependent. A mechanistic understanding of these interactions will therefore help us to extrapolate their effects over larger areas and longer time scales (Goodwin and Fahrig 1998). By way of illustration, the implications of spatial density dependence for the population dynamics of our study species depend partly on its biological cause. For L. dalli, the implications depend on how predators cause densitydependent mortality. For example, an aggregative response by predators may, or may not, lead to temporal 
stabilization of $L$. dalli populations. The consequences are uncertain because an aggregative response might simply redistribute mortality in space within a set of habitat patches without changing its overall level, which could preclude population regulation over time. In contrast, a type III functional response, particularly if it occurs because predators switch from gobies to other prey at low goby densities, is more likely to lead to regulation of abundance over time. Continued attention to the interactions producing density dependence will thus be a key part of our efforts to develop a better understanding population dynamics.

\section{ACKNOWLEDGMENTS}

Many thanks to all of those who helped us with field work, including S. Anderson, R. Buckley, B. Byrne, D. Canestro, M. Carr, B. Fredericks, I. Greenspan, M. Hixon, A. Karpenske, E. Kintzing, J. Malone, C. McKinney, Y. Springer, C. Tinus, T. Trejo, E. Tynes, and especially G. Almany. We are also grateful for the excellent logistical support provided by the staffs at the Wrigley Institute for Environmental Studies, the Caribbean Marine Research Center and Guana Island, and to M. Carr and M. Hixon for use of their assistants and their artificial reefs at Lee Stocking Island (funded by their grants from NOAANURP and NSF). The manuscript benefited from the comments of two anonymous reviewers. This research was supported by grants to G. Forrester from the National Science Foundation (OCE 96-18011) and the Falconwood Corporation.

\section{Literature Cited}

Alvarez-Buylla, E. R. 1994. Density dependence and patch dynamics in tropical rain forests: matrix models and applications to a tree species. American Naturalist 143:155-191.

Auerbach, M., E. Connor, and S. Mopper. 1995. Minor miners and major minors: population dynamics of leaf-mining insects. Pages 83-110 in N. Cappuccino and P. Price, editors. Population dynamics: new approaches and synthesis. Academic Press, San Diego, California, USA.

Bailey, K. 1994. Predation on juvenile flatfish and recruitment variability. Netherlands Journal Of Sea Research 32: 175-189.

Bailey, K., and E. Houde. 1989. Predation on eggs and larvae of marine fishes and the recruitment problem. Advances in Marine Biology 25:1-83.

Begon, M., M. Mortimer, and D. J. Thompson. 1996. Population ecology: a unified study of animals and plants. Blackwell Science, Oxford, UK.

Behrents, K. C. 1983. The comparative ecology and interactions between two sympatric gobies (Lythrypnus dalli and Lythrypnus zebra). Dissertation. University of Southern California, Los Angeles, California, USA.

Behrents, K. C. 1987. The influence of shelter availability on recruitment and early juvenile survivorship of Lythrypnus dalli Gilbert (Pisces: Gobiidae). Journal of Experimental Marine Biology and Ecology 107:45-59.

Caley, M. J., M. H. Carr, M. A. Hixon, T. P. Hughes, G. P. Jones, and B. A. Menge. 1996. Recruitment and the population dynamics of open marine populations. Annual Review of Ecology and Systematics 27:477-500.

Cappuccino, N. 1991. Density dependence in the mortality of phytophagous insects on goldenrod (Solidago altissima). Environmental Entomology 20:1121-1128.

Cappuccino, N. 1992. The nature of population stability in Eurosta solidaginis, a nonoutbreaking herbivore of goldenrod. Ecology 73:1792-1801.

Carr, M. H., and M. A. Hixon. 1995. Predation effects on early post-settlement survivorship of coral-reef fishes. Marine Ecology Progress Series 124:31-42.
Crawley, M. J. 1992. Natural enemies: the population biology of predators, parasites, and diseases. Blackwell Scientific Publications, Oxford, UK.

Cushing, D. H. 1995. Population production and regulation in the sea: a fisheries perspective. Cambridge University Press, Cambridge, UK.

Dayton, P. K., and J. S. Oliver. 1980. An evaluation of experimental analysis of population and community patterns in benthic marine environments. Pages 93-120 in K. Tenore, and B. C. Coull, editors. Marine benthic dynamics. University of South Carolina Press, Columbia, South Carolina, USA.

Dempster, J. 1983. The natural control of populations of butterflies and moths. Biological Reviews 58:461-481.

Doherty, P. J. 1982. Some effects of density on the juveniles of two species of tropical territorial damselfishes. Journal of Experimental Marine Biology and Ecology 65:249-261.

Doherty, P. J. 1983. Tropical territorial damselfishes: is density limited by aggression or recruitment? Ecology 64:176-190.

Elliott, J. M. 1994. Quantitative ecology and the brown trout. Oxford University Press, Oxford, UK.

Elliott, J., and M. A. Hurley. 1998. Population regulation in adult, but not juvenile, resident trout Salmo trutta in a lake district stream. Journal of Animal Ecology 67:280-286.

Forrester, G. E. 1990. Factors influencing the juvenile demography of a coral reef fish. Ecology 71:1666-1681.

Forrester, G. E. 1995. Strong density-dependent survival and recruitment regulate the abundance of a coral reef fish. Oecologia 103:275-282.

Frederick, J. L. 1997. Evaluation of fluorescent elastomer injection as a method for marking small fish. Bulletin of Marine Science 61:399-408.

Freeman, B., and D. Smith. 1990. Variation of density dependence with spatial scale in the leaf mining fly Liriomyza commelinae (Diptera: Agromyzidae). Ecological Entomology 15:265-274.

Gaston, K. J., and J. H. Lawton. 1987. A test of statistical techniques for detecting density dependence in sequential censuses of animal populations. Oecologia 74:404-410.

Goodwin, B., and L. Fahrig. 1998. Spatial scaling and aninmal population dynamics. Pages 193-206 in D. Peterson and T. Parker, editors. Ecological scale: theory and applications. Columbia University Press, New York, New York, USA.

Gulland, J. 1977. Fish population dynamics. Wiley, London, UK.

Harrison, S., and N. Cappuccino. 1995. Using density-manipulation experiments to study population regulation. Pages 131-172 in N. Cappuccino and P. W. Price, editors. Population dynamics: new approaches and synthesis. Academic Press, San Diego, USA.

Hassell, M. P. 1986. Detecting density dependence. Trends in Ecology and Evolution 1:90-93.

Hassell, M. P. 1987. Detecting regulation in patchily distributed animal populations. Journal of Animal Ecology 56: 705-713.

Hassell, M. P., J. Latto, and R. M. May. 1989. Seeing the wood for the trees: detecting density dependence from existing life table studies. Journal of Animal Ecology 58:883-892.

Hassell, M. P., J. Latto, and R. M. May. 1989. Seeing the wood for the trees: detecting density dependence from existing life table studies. Journal of Animal Ecology 58:883892.

Hassell, M. P., and R. May. 1974. Aggregation of predators and insect parasites and its effect on stability. Journal of Animal Ecology 43:567-594.

Heads, P. A., and J. H. Lawton. 1983. Studies on the natural enemy complex of the holly leaf-miner: the effects of scale on the detection of aggregative responses and the implications for biological control. Oikos 40:267-276.

Hixon, M. A., and M. H. Carr. 1997. Synergistic predation, 
density dependence, and population regulation in marine fish. Science 277:946-949.

Holling, C. 1959. The components of predation as revealed by a study of small-mammal predation of the European pine sawfly. Canadian Entomologist 91:293-320.

Hopper K. R., J. E. Powell, and E. G. King. 1991. Spatial density dependence in parasitism of Heliothis virescens (Lepidoptera, Noctuidae) by Microplitis croceipes (Hymenoptera, Braconidae) in the field. Environmental Entomology 20:292-302.

Hunt von Herbing, I., and W. Hunte. 1991. Spawning and recruitment of the bluehead wrasse Thalassoma bifasciatum in Barbados, West Indies. Marine Ecology Progress Series 72:49-58.

Jones, G. P. 1984. Population ecology of the temperate reef fish Pseudolabrus celidotus Bloch \& Schneider (Pisces: Labridae) II: factors influencing adult density. Journal of Experimental Marine Biology and Ecology 75:277-303.

Jones, G. P. 1987a. Competitive interactions among adults and juveniles in a coral reef fish. Ecology 68:1534-1547.

Jones, G. P. 1987b. Some interactions between residents and recruits in two coral reef fishes. Journal of Experimental Marine Biology and Ecology 114:169-182.

Jones, G. P. 1988. Experimental evaluation of the influence of habitat structure and competitive interactions on the juveniles of two coral reef fishes. Journal of Experimental Marine Biology and Ecology 123:115-126.

Murdoch, W. W. 1970. Population regulation and population inertia. Ecology 51:497-502.

Murdoch, W. W. 1994. Population regulation in theory and practice. Ecology 75:271-287.

Myers, R. A. 1997. Recruitment variation in fish populations assessed using meta-analysis. Pages 451-468 in R. Chambers and E. Trippel, editors. Early life history and recruitment in fish populations. Chapman and Hall, London, UK.

Myers, R. A., and N. G. Cadigan 1993. Density-dependent juvenile mortality in marine demersal fish. Canadian Journal of Fisheries and Aquatic Sciences 50:1576-1590.

Nicholson, A. 1957. The self adjustment of populations to change. Cold Spring Harbor Symposium in Quantitative Biology 22:153-172.

Peterson, C. H. 1979. Predation, competitive exclusion, and diversity in the soft-sediment benthic communities of estuaries and lagoons. Pages 233-264 in R. J. Livingston, editor. Ecological processes in coastal and marine systems. Plenum, New York, New York, USA.

Possingham, H. P., S. Tuljapurkar, J. Roughgarden, and M. Wilks. 1994. Population cycling in space-limited organisms subject to density-dependent predation. American Naturalist 143:563-582.

Randall, J. 1967. Food habits of reef fishes of the West Indies. Studies in tropical Oceanography 5:665-847.

Ray, C., and A. Hastings. 1996. Density dependence-are we searching at the wrong spatial scale? Journal of Animal Ecology 65:556-566.

Rijnsdorp, A. D. 1994. Population-regulating processes during the adult phase in flatfish. Netherlands Journal of Sea Research 32:207-223.

Rothman, L. D., and D. C. Darling. 1990. Parasitoids of the goldenrod gall moth: effects of scale on spatial density dependence. Oecologia 83:1-6.

Sale, P. F. 1991. The ecology of fishes on coral reefs. Academic Press, San Diego, USA.

Sano, M. 1997. Temporal variation in density dependence: recruitment and postrecruitment demography of a temperate zone sand goby. Journal of Experimental Marine Biology and Ecology 214:67-84.

Schmitt, R. J., and S. J. Holbrook. 1996. Local-scale patterns of larval settlement in a planktivorous damselfish-do they predict recruitment. Marine and Freshwater Research 47: 449-463.

Schmitt, R. J., and S. J. Holbrook. 1999a. Mortality of juvenile damselfish: implications for assessing processes that determine abundance. Ecology 80:35-50.

Schmitt, R. J., and S. J. Holbrook. 1999b. Settlement and recruitment of three damselfish species: larval delivery and competition for shelter space. Oecologia 118:76-86.

Sinclair, A. R. E. 1989. Population regulation in animals. Pages 197-242 in J. Cherrett, editor. Ecological concepts. Blackwell Scientific, Oxford, UK.

Sponaugle, S., and R. K. Cowen. 1994. Larval durations and recruitment patterns of two Caribbean gobies (Gobiidae): contrasting early life histories in demersal spawners. Marine Biology 120:133-143.

St Mary, C. M. 1993. Novel sexual patterns in two simultaneously hermaphroditic gobies, Lythrypnus dalli and Lythrypnus zebra. Copeia 1993:1062-1072.

Steele, M. A. 1996. Effects of predators on reef fishes: separating cage artifacts from effects of predation. Journal of Experimental Marine Biology and Ecology 198:249-267.

Steele, M. A. 1997. Population regulation by post-settlement mortality in two temperate reef fishes. Oecologia 112:64-74.

Steele, M. A. 1998. The relative importance of predation and competition in two reef fishes. Oecologia 115:222-232.

Steele, M. A. 1999. Effects of shelter and predators on reef fishes. Journal of Experimental Marine Biology and Ecology 233:65-79.

Stewart-Oaten, A., and W. W. Murdoch. 1990. Temporal consequences of spatial density dependence. Journal of Animal Ecology 59:1027-1045.

Stiling, P. 1988. Density-dependent processes and key factors in insect populations. Journal of Animal Ecology 57:581-594.

Stiling, P., A. Throckmorton, J. Silvanima, and D. R. Strong. 1991. Does spatial scale affect the incidence of density dependence-a field test with insect parasitoids. Ecology 72:2143-2154.

Tonn, W. M., I. J. Holopainen, and C. A. Paszkowski. 1994. Density-dependent effects and the regulation of crucian carp populations in single species ponds. Ecology 75:824-834.

Tupper, M., and R. G. Boutilier. 1995. Effects of conspecific density on settlement, growth and post-settlement survival of a temperate reef fish. Journal of Experimental Marine Biology and Ecology 191:209-222.

Tupper, M., and W. Hunte. 1994. Recruitment dynamics of coral reef fishes in Barbados. Marine Ecology Progress Series 108:225-235.

Turchin, P. 1990. Rarity of density dependence or population regulation with lags. Nature 344:660-663.

Underwood, A. J., and E. J. Denley. 1984. Paradigms, explanations, and generalizations in models for the structure of intertidal communities on rocky shores. Pages 151-180 in D. R. Strong, D. Simberloff, L. G. Abele, and A. B. Thistle, editors. Ecological communities: conceptual issues and the evidence. Princeton University Press, Princeton, New Jersey, USA.

Varley, G. C., G. R. Gradwell, and M. P. Hassell. 1973. Insect population ecology: an analytical approach. Blackwell Scientific, Oxford, UK.

Virnstein, R. W. 1978. Predator caging experiments in soft sediments: caution advised. Pages 261-273 in M. L. Wiley, editor. Estuarine interactions. Academic Press, New York, New York, USA.

Weatherley, A. H. 1972. Growth and ecology of fish populations. Academic Press, London, UK.

Wiley, J. 1973. Life history of the western North American goby, Coryphopterus nicholsii (Bean). Transactions of the San Diego Society for Natural History 17:187-208. 